\title{
Introduction to the Special Section on Patterns of Strength and Weakness
}

\author{
James Hiramoto ${ }^{1}$
}

Published online: 22 February 2017

(C) California Association of School Psychologists 2017

McGill and Busse (2016a), Christo, D'Incau and Ponzuric (2016) response, and McGill and Busse (2016b) rejoinder are thought-provoking articles regarding CASP position paper on Patterns of Strength and Weakness (Christo and Jones 2014). They raise important questions for us to address: not only how should we define evidenced-based practice (EBP) but also ultimately what to do about the requirements that the law places on us with respect to our practice and what does current research show for its efficacy?

Although McGill and Busse (2016a, b) do not put forth a definition per se of what EBP is, what is described is consistent to what is called "Severe EBP" by Shaw and D'Intino (2017 January/February), in their NASP Communique article, "Evidence-Based Practice and the Reproducibility Crisis in Psychology." Therefore, I have two concerns about the statement in McGill and Busse's (2016b) rejoinder when they write:

"It should be noted that proponents of the PSW model frequently invoke the term comprehensive assessment in response to critiques in the professional literature (e.g., Flanagan et al. 2011; Hale et al. 2010). However, it has long been shown that assessment teams disproportionally weigh certain pieces of information at the expense of others when making the yes/ no decisions required in the SLD identification process (see Peterson \& Shinn, 2002)" for at least two reasons.

One is that McGill and Busse are quick to dismiss all of the data that must go into a "comprehensive assessment." They cite Peterson \& Shinn (2002) as incontrovertible proof of assessment team bias for specific pieces of data in LD decision-

James Hiramoto

drhiramoto@gmail.com

1 Brentwood Union School District, Brentwood, CA, USA making. What may not be clear is that, this study is based on "48 fourth-grade, school-identified LD students from a highachieving and a low-achieving school district in Minnesota. Students were tested with a short form of the WISC-III and two measures of reading, and the resulting discrepancies were matched to students' school LD classification." Their argument does not appear to account for the qualitative and quantitative background data that is not standardized but rather criterion based or based on the professional judgment of observers. For instance, classroom data can shed doubt on the validity of standardized test scores, especially when nationally normed academic standardized tests have been normed across states prior to there being a common standard of educational achievement for each grade level.

Second is that they use results from a decade and a half ago to pass judgment on professional practice today. They use studies that go back to the 1990's to talk about the shortcomings of subtest-level profile analyses without addressing the fact that the tests themselves were not based on CHC theory, which specifically looks at broad stratum II factors or alternately PASS theory that has a completely different set of factors. The tests that are being criticized for their subtest-level profile analyses are based on older editions of tests (especially the Wechsler tests), which were derived from the Army Alpha and Army Beta test, given by the US Army in 1919 and developed with no theoretical underpinning. To be fair, they do report on studies that are more recent, even one in 2016 (Kranzler, Floyd, Benson, Zaboski, \& Thibodaux, 2016), but even the data that the 2016 study used was from the WJ-III Cognitive and Achievement Tests and a very early version of the X-BASS.

To their credit, McGill and Busse do address the inherent problem of tests of overall intelligence/cognitive ability also being quality measures of broad stratum II factors. What part of the shared variance between these subtests that make up 
Table 1 Comparison of Laws California Ed. Code CA EC 56337
Code of Federal Regulations CFR Sec. 300.307

“(b) Notwithstanding any other law and pursuant to Section 1414(b) (6) of Title 20 of the United States Code, in determining whether a pupil has a specific learning disability as defined in subdivision (a), a local educational agency is not required to take into consideration whether a pupil has a severe discrepancy between achievement and intellectual ability in oral expression, listening comprehension, written expression, basic reading skill, reading comprehension, mathematical calculation, or mathematical reasoning.

(c) In determining whether a pupil has a specific learning disability, a local educational agency may use a process that determines if the pupil responds to scientific, research-based intervention as a part of the assessment procedures described in

Section 1414(b)(2) and (3) of Title 20 of the United States Code and covered in Sections 300.307 to 300.311, inclusive, of Title 34 of the Code of Federal Regulations."

California Code of Regulations

CCR 3030 (b) (10)

(10) Specific learning disability means a disorder in one or more of the basic psychological processes involved in understanding or in using language, spoken or written, that may have manifested itself in the imperfect ability to listen, think, speak, read, write, spell, or do mathematical calculations, including conditions such as perceptual disabilities, brain injury, minimal brain dysfunction, dyslexia, and developmental aphasia. The basic

psychological processes include attention, visual processing, auditory

processing, phonological processing, sensory-motor skills, cognitive abilities including association, conceptualization and expression.

(A) Specific learning disabilities do not include learning problems that are primarily the result of visual, hearing, or motor disabilities, of intellectual disability, of emotional disturbance, or of environmental, cultural, or economic disadvantage.

(B) In determining whether a pupil has a specific learning disability, the public agency may consider whether a pupil has a severe discrepancy between intellectual ability and achievement in oral expression, listening comprehension, written expression, basic reading skill, reading comprehension, mathematical calculation, or mathematical reasoning. The decision as to whether or not a severe discrepancy exists shall take into account all relevant material which is available on the pupil. No single score or product of scores, test or procedure shall be used as the sole criterion for the decisions of the IEP team as to the pupil's eligibility for special education. In determining the existence of a severe discrepancy, the IEP team shall use the following procedures: (a) General. A State must adopt, consistent with Sec. 300.309 , criteria for determining whether a child has a specific learning disability as defined in Sec. 300.8 (c)(10). In addition, the criteria adopted by the State--

(1) Must not require the use of a severe discrepancy between intellectual ability and achievement for determining whether a child has a specific learning disability, as defined in Sec. 300.8(c)(10);

(2) Must permit the use of a process based on the child's response to scientific, research-based intervention; and

(3) May permit the use of other alternative research-based procedures for determining whether a child has a specific learning disability, as defined in Sec. 300.8(c)(10).

(b) Consistency with State criteria. A public agency must use the State criteria adopted pursuant to paragraph (a) of this section in determining whether a child has a specific learning disability.

(Authority: 20 U.S.C. 1221e-3; 1401(30); 1414(b)(6))

\section{CFR Sec 300. 8}

(10) Specific learning disability. (i) General. Specific learning disability means a disorder in one or more of the basic psychological processes involved in understanding or in using language, spoken or written, that may manifest itself in the imperfect ability to listen, think, speak, read, write, spell, or to do mathematical calculations, including conditions such as perceptual disabilities, brain injury, minimal brain dysfunction, dyslexia, and developmental aphasia.

(ii) Disorders not included. Specific learning disability does not include learning problems that are primarily the result of visual, hearing, or motor disabilities, of mental retardation, of emotional disturbance, or of environmental, cultural, or economic disadvantage.

\section{[This Section no longer exists in the Code Federal} Regulations 2004]

From Michael v. Hawaii 656F.3d 1057 (9th Cir. 2011) [and repeated again in M.M. v. Lafayette Sch. Dist., No. 12-15769 (9th Cir. 2014) consolidated appeals from M.M. v. Lafayette Sch. Dist., 681F.3d 1082 (9th Cir. 2012)]

"Over the last decade, scientific research has established that the "severe discrepancy model" is not necessarily a good indicator of whether a child has a learning disability. See Weber, supra at123-27; H.R.Rep. No.108-77 at 112(2003). The "severe discrepancy model" is based on the premise that underperforming students with relatively high IQs must have a learning disability, whereas underperforming students with low IQs are just" slow. "See Suzanne Wilhelm, Accommodating Mental Disabilities in Higher Education: A Practical Guide to ADA Requirements, * 1061106132 J. L. Educ. 217 (2003). This premise is subject to dispute because intelligence testing is not the best indicator of academic potential. See Susan E. McGuigan, 
Table 1 (continued)

1. When standardized tests are considered to be valid for a specific pupil, a severe discrepancy is demonstrated by: first, converting into common standard scores, using a mean of 100 and standard deviation of 15 , the achievement test score and the intellectual ability test score to be compared; second, computing the difference between these common standard scores; and third, comparing this computed difference to the standard criterion which is the product of 1.5 multiplied by the standard deviation of the distribution of computed differences of students taking these achievement and ability tests.

1. When standardized tests are considered to be valid for a specific pupil, a severe discrepancy is demonstrated by: first, converting into common standard scores, using a mean of 100 and standard deviation of 15 , the achievement test score and the intellectual ability test score to be compared; second, computing the difference between these common standard scores; and third, comparing this computed difference to the standard criterion which is the product of 1.5 multiplied by the standard deviation of the distribution of computed differences of students taking these achievement and ability tests. A computed difference which equals or exceeds this standard criterion, adjusted by one standard error of measurement, the adjustment not to exceed 4 common standard score points, indicates a severe discrepancy when such discrepancy is corroborated by other assessment data which may include other tests, scales, instruments, observations and work samples, as appropriate.

2. When standardized tests are considered to be invalid for a specific pupil, the discrepancy shall be measured by alternative means as specified on the assessment plan.

3. If the standardized tests do not reveal a severe discrepancy as defined in subdivisions 1 . or 2 . above, the IEP team may find that a severe discrepancy does exist, provided that the team documents in a written report that the severe discrepancy between ability and achievement exists as a result of a disorder in one or more of the basic psychological processes. The report shall include a statement of the area, the degree, and the basis and method used in determining the discrepancy. The report shall contain information considered by the team which shall include, but not be limited to:

(i) Data obtained from standardized assessment instruments;

(ii) Information provided by the parent;

(iii) Information provided by the pupil's present teacher;

(iv) Evidence of the pupil's performance in the regular and/or special education classroom obtained from observations, work samples, and group test scores;

(v) Consideration of the pupil's age, particularly for young children; and
Documenting Learning Disabilities: Law Schools Responsibility to Set Clear Guidelines, 36J. C. U. L. 191, 196. As a result, reliance on the "severe discrepancy model" tends to under-identify children with below average intelligence. Id. Moreover, education experts have criticized the model as unreliable, invalid, easily undermined, and harmful because it delays early treatment. See Weber, supra at124.

To address these growing concerns, Congress eliminated the "severe discrepancy" requirement when it reauthorized IDEA in 2004. See 20 U.S.C. $\$ 1414(b)(6)(A)$ ("[W]hen determining whether a child has a specific learning disability..., a local educational agency shall not be required to take into consideration whether a child has a severe discrepancy between achievement and intellectual ability in oral expression, listening comprehension, written expression, basic reading skill, reading comprehension, mathematical calculation, or mathematical reasoning."); see also H.R. Rep. No. $108-77$ at 112 (2003) (indicating that Congress is "discouraged by the widespread reliance on the IQ-achievement discrepancy model that serves as the determining factor of whether a child has a specific learning disability")."

\section{CFR Sec 300.309}

“(a) The group described in $\S 300.306$ may determine that a child has a specific learning disability, as defined in $\S 300.8$ (c) (10), if

(1) The child does not achieve adequately for the child's age or to meet State-approved grade-level standards in one or more of the following areas, when provided with learning experiences and instruction appropriate for the child's age or State-approved grade-level standards:

“(i) Oral expression.

(ii) Listening comprehension.

(iii) Written expression.

(iv) Basic reading skill.

(v) Reading fluency skills.

(vi) Reading comprehension.

(vii) Mathematics calculation.

(viii) Mathematics problem solving

(2)(i) The child does not make sufficient progress to meet age or State-approved grade-level standards in one or more of the areas identified in paragraph (a)(1) of this section when using a process based on the child's response to scientific, research-based intervention;

or

(ii) The child exhibits a pattern of strengths and weaknesses in performance, achievement, or both, relative to age, State-approved grade level standards, or intellectual development, that is determined by the group to be relevant to the identification of a specific learning disability, using appropriate assessments, consistent with Sec. Sec. 300.304 and 300.305; 
Table 1 (continued)

Code of Federal Regulations CFR Sec. 300.307

(vi) Any additional relevant information.

4. A severe discrepancy shall not be primarily the result of limited school experience or poor school attendance.

(C) Whether or not a pupil exhibits a severe discrepancy as described in subdivision (b) (10) (B) above, a pupil may be determined to have a specific learning disability if:

1. The pupil does not achieve adequately for the pupil's age or to meet State-approved grade-level standards in one or more of the following areas, when provided with learning experiences and instruction appropriate for the pupil's age or State-approved grade-level standards:

(i) Oral expression.

(ii) Listening comprehension.

(iii) Written expression.

(iv) Basic reading skill.

(v) Reading fluency skills.

(vi) Reading comprehension.

(vii) Mathematics calculation.

(viii) Mathematics problem solving, and

2.(i) The pupil does not make sufficient progress to meet age or State-approved grade-level standards in one or more of the areas identified in subdivision (b) (10) (C)(1) of this section when using a process based on the pupil's response to scientific, research-based intervention; or

(ii) The pupil exhibits a pattern of strengths and weaknesses in performance, achievement, or both, relative to age, State-approved grade-level standards, or intellectual development, that is determined by the group to be relevant to the identification of a specific learning disability, using appropriate assessments, consistent with 34 C.F.R. sections 300.304 and 300.305; and

3. The findings under subdivisions (b) (10) (C)(1) and (2) of this section are not primarily the result of:

(i) A visual, hearing, or motor disability;

(ii) Intellectual disability;

(iii) Emotional disturbance;

(iv) Cultural factors;

(v) Environmental or economic disadvantage; or

(vi) Limited English proficiency.

4. To ensure that underachievement in a pupil suspected of having a specific learning disability is not due to lack of appropriate instruction in reading or math, the group making the decision must consider:

(i) Data that demonstrate that prior to, or as a part of, the referral process, the pupil was provided appropriate instruction in regular education settings, delivered by qualified personnel; and

(ii) Data-based documentation of repeated assessments of achievement at reasonable intervals, reflecting formal and

(3) The group determines that its findings under paragraphs (a)(1) and (2) of this section are not primarily the result of -

(i) A visual, hearing, or motor disability;

(ii) Mental retardation;

(iii) Emotional disturbance;

(iv) Cultural factors;

(v) Environmental or economic disadvantage; or

(vi) Limited English proficiency.

(b) To ensure that underachievement in a child suspected of having a specific learning disability is not due to lack of appropriate instruction in reading or math, the group must consider, as part of the evaluation described in $\S \S 300.304$ through 300.306

(1) Data that demonstrate that prior to, or as a part of, the referral process, the child was provided appropriate instruction in regular education settings, delivered by qualified personnel; and

(2) Data-based documentation of repeated assessments of achievement at reasonable intervals, reflecting formal assessment of student progress during instruction, which was provided to the child's parents.

(c) The public agency must promptly request parental consent to evaluate the child to determine if the child needs special education and related services, and must adhere to the time frames described in $\S \S 300.301$ and 300.303 , unless extended by mutual written agreement of the child's parents and a group of qualified professionals, as described in $\S$ 300.306(a)(1)

(1) If, prior to a referral, a child has not made adequate progress after an appropriate period of time when provided instruction, as described in paragraphs (b)(1) and (b)(2) of this section; and

(2) Whenever a child is referred for an evaluation. (Authority: 20 U.S.C. 1221e-3; 1401(30); 1414(b)(6)) 
Table 1 (continued)

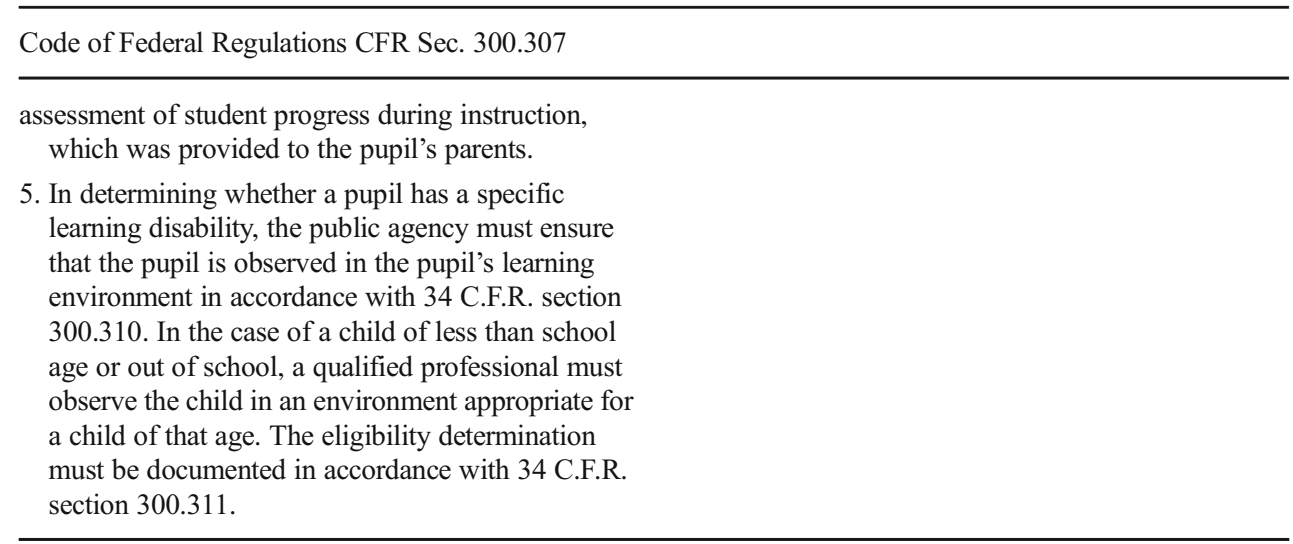

broad factors is not also shared by an overall factor " $g$ " if it exists, or a high order executive functioning factor that spans a subset of subtests that from varying broad factors? The difference between their view and mine is that I believe that professionals, given everything that goes into a comprehensive assessment, can make reasonable judgments about what specific broad factors might be related to a child's academic weakness when compared to overall ability. Getting this information from a comprehensive assessment that includes RIOT (Leung, 1993; Record review, Interviews, Observation, and Testing - standard and non-standardized) is far easier than they would have us believe. It is what makes school psychologists the professionals they are, rather than psychometricians.

The road of Severe EBP that McGill and Busse appear to espouse is not paved with gold. The cautionary tale is found in Shaw and D'Intino (2017 January/February) NASP Communique article, where:

"This interpretation of EBPs leads to a criticism of robotic rather than professional implementation of interventions. There is no opportunity to deviate from the protocol or methodologies of supporting studies. This is obviously a problem when the context, needs of the clientele or clients, resources, clinical expertise, the cultural environment of the institution where interventions are being provided, and a host of other variables are not considered in the severe form of EBP. Furthermore, it is unlikely that the sampling, context, and specifics of the presenting problem are exactly the same for the research group as for the clinical group to which the EBP is being applied. Again, the severe interpretation of EBP is not consistent with the original intent of the concept. The severe form of EBP is frequently rejected, and like the weak form, results in an environment where innovation is unlikely to take place."

Despite this caution about EBP, McGill and Busse are to be commended for raising their questions about the efficacy of PSW as they force us to look at the requirements that the law places on us with respect to our practice. Table 1 is a side-byside comparison of California Education Code and California Code of Regulation to the Code of Federal Regulation.
In regards to the regulations, while McGill and Busse's (2016a) statement, "that the federal definition of SLD does not explicitly require that cognitive processing deficits must be measured or assessed or that standardized tests are required, although it is required in a minority of states such as California (Lichtenstein 2014)." is true given the option of RTI, it is difficult to argue that the law does not see its importance. The underlying principle that basic cognitive processes impact academic achievement is clearly implicit it the Code of Federal and California Code of Regulations (CFR Sec. 300.8 (10) (i)) and CCR 3030(a).

"Specific learning disability means a disorder in one or more of the basic psychological processes involved in understanding or in using language, spoken or written, that may [have] manifest itself in the imperfect ability to listen, think, speak, read, write, spell, or [to] do mathematical calculations, including conditions such as perceptual disabilities, brain injury, minimal brain dysfunction, dyslexia, and developmental aphasia."

The sheer number of fair hearings and court cases in California where the question of whether or not enough evidence of a processing deficit/disorder is present for the determination of an SLD easily in the thousands. McGill and Busse would be right to claim that the reason for this is California's stubborn insistence of maintaining the discrepancy model, which was abandoned by the federal government in the 2004 IDEIA reauthorization. I agree completely with this. The achievement/ability discrepancy is a failed model and the state's insistence on it undermines our professional practice.

So is RtI the only option that would meet Severe EBP criteria? Well...no. The U.S. Department of Education, National Center for Education Evaluation, and Regional Assistance's November 2015 publication, "Evaluation of Response to Intervention Practices for Elementary School Reading" concluded that RtI was detrimental for underperforming students. It also uncovered some dangerous practices such as one assessment or test determining RtI services and one size fits all interventions (Balu et al. 2015). 
So, if evidence points to everything not working what do we do? We need to keep looking and doing the best that we can, with what we know. Ventura County SELPA has evaluated current research for its COMPARES section of their PSW Model (Ventura County SELPA 2015). I would hope our readers take the opportunity to review this as well. Shaw and D'Intino (2017) expressed it well that:

"School psychologists play a unique role as bilateral mediators between research and intervention and as such, have a responsibility to apply a balanced approach to EBP and to evaluate effectiveness to inform future research and practice. The days of focusing on the false dichotomy of research versus practice are over. In the age of EBP, generalizable research and implementation to practice as a seamless process is the future of school psychology. In taking advantage of this opportunity to refine the standards of research and practice, better services can be offered to patients, clients, and students."

Again, the questions raised in these articles are important ones for our profession. We can only improve when we look at what we do with a critical eye.

\section{References}

Balu, R., Zhu, P., Doolittle, F., Schiller, E., Jenkins, J. \& Gersten R. (2015). Evaluation of response to intervention practices for elementary school reading. U.S. Department of Education, National Center for Education Evaluation and Regional Assistance. November.

Christo, C., \& Jones, J. (2014). Specific learning disabilities and patterns of strengths and weaknesses (CASP position paper). Retrieved from California Association of School Psychologists Website: http:// www.casponline.org.

Christo, C., D'Incau, B. J., \& Ponzuric, J. (2016). Response to McGill and Busse, "When Theory Trumps Science: A Critique of the PSW Model for SLD Identification." Contemporary School Psychology. Advance online publication.

Hale, J. Alfonso, V., Berninger, V., Bracken, B., Christo, C., Clark, E., Yalof, J. (2010). Critical issues in response-to-intervention, comprehensive evaluation, and specific learning disabilities identification and intervention: An expert white paper consensus. Learning
Disabilities Quarterly, 33, 223-236. doi: 10.1177/ 073194871003300310

Kranzler, J. H., Floyd, R. G., Benson, N., Zaboski, B., \& Thibodaux, L. (2016). Classification agreement analyses of cross-battery assessment in the identification of specific learning disabilities in children and youth. International Journal of School \& Educational Psychology. Published on-line March 2016 pp124-136.

Leung, B. (1993). Back to basics: assessment is a R.I.O.T.! NASP Communiqué, 22(3), 1-6 Retrieved from http:// www.nasponline.org/publications/cq/.

Lichtenstein, R. (2014). Best practices in identifying learning disabilities. In P. L. Harrison \& A. Thomas (Eds.), Best practices in school psychology: data-based and collaborative decision making (pp. 331-354). Bethesda: National Association of School Psychologists Publications.

McGill, R. J., \& Busse, R. T. (2016a). When theory trumps science: a critique of the PSW model for SLD identification. Contemporary School Psychology. Advance online publication.

McGill, R. J., \& Busse, R. T. (2016b). A Rejoinder on the PSW model for SLD identification: still soncerned. Contemporary School Psychology. Advance online publication.

Peterson, M. H., \& Shinn, M. R. (2002). Severe discrepancy models: which best explains school identification practices for learning disabilities? School Psychology Review, 31, 459-476 Retrieved from http:www.naspoline.org.

Shaw, S.R. \& D'Intino, J. (2017) January-February. Evidence-based practice and the reproducibility crisis in psychology, NASP Communique, Vol. 45 No. 5 http://www.nasponline.org/resourcesand-publications/periodicals/communiqu\%C3\%A9-volume-45number-5-(january/february-2017)/evidence-based-practice-andthe-reproducibility-crisis-in-psychology

Ventura County SELPA (2015). The Ventura County SELPA pattern of strengths and weaknesses model for specific learning disability eligibility procedural manual.

Dr. James Hiramoto has taught, and consulted with well over a thousand educators, from paraeducators to superintendents, including those working on teaching credentials to those finishing their doctorates as school psychologists. With nearly two decades of experience as a school psychologist, and nearly a decade as a director/professor of a masters and doctoral school psychology program, he provides professional development trainings and assessments on some of California's most difficult-toserve students. 